\title{
Estimativas de tamanho de parcelas para avaliação de descritores fenotípicos em bananeira
}

\author{
Sérgio Luiz Rodrigues Donato(1), Dalmo Lopes de Siqueira(2), Sebastião de Oliveira e Silva ${ }^{(3)}$, \\ Paulo Roberto Cecon $^{(2)}$, João Abel da Silva(1) e Luiz Carlos Chamhum Salomão(2)
}

\begin{abstract}
(1)Escola Agrotécnica Federal Antônio José Teixeira, Caixa Postal 09, Distrito de Ceraima, CEP 46430-000 Guanambi, BA. E-mail: sergiodonato@eafajt.gov.br, joaoabel@eafajt.gov.br (2)Universidade Federal de Viçosa, Avenida P.H. Rolfs, s/nº, CEP $36570-000$ Viçosa, MG. E-mail: siqueira@ufv.br, cecon@dpi.ufv.br, Isalomao@ufv.br ${ }^{(3)}$ Embrapa Mandioca e Fruticultura Tropical, Caixa Postal 07, CEP 44380-000 Cruz das Almas, BA. E-mail: ssilva@cnpmf.embrapa.br
\end{abstract}

Resumo - O objetivo deste trabalho foi estimar o tamanho adequado de parcelas experimentais, para avaliação de descritores fenotípicos em bananeira, a partir de um ensaio de uniformidade com a cultivar Tropical, no espaçamento de $3 \times 2 \mathrm{~m}$, em área útil com nove fileiras de 40 plantas. Foram avaliados: altura da planta; perímetro do pseudocaule; número de filhos emitidos e número de folhas vivas, no florescimento e na colheita; peso do cacho e das pencas; número de pencas e de frutos; peso da segunda penca; e peso, comprimento e diâmetro do fruto, em dois ciclos de produção. As plantas, consideradas unidades básicas, foram combinadas para formar diferentes tamanhos de parcelas. Os dados foram submetidos à análise de variância em modelo hierárquico. $\mathrm{O}$ tamanho da parcela foi estimado pelos métodos da máxima curvatura, máxima curvatura modificado e comparação de variâncias. Determinaram-se o índice de heterogeneidade do solo e a diferença detectável entre médias de tratamentos. A variabilidade aumentou entre os ciclos, com reflexos nos tamanhos de parcela, que variaram com o método utilizado, a variável avaliada e o ciclo de produção. O método da máxima curvatura modificado apresenta estimativas mais ajustadas. Parcelas com seis unidades básicas (36 m²) são apropriadas para avaliar, com precisão, os descritores fenotípicos em bananeira.

Termos para indexação: Musa spp., estatística agrícola, morfologia, produção.

\section{Estimates of plot size for the evaluation of phenotipics descriptors in banana}

\begin{abstract}
The aim of this work was to estimate the adequate size of experimental plots, for the evaluation of phenotypic descriptors in banana, from a trial of uniformity with the cultivar Tropical, in the spacing of $3 \times 2 \mathrm{~m}$, in a useful area with nine rows of 40 plants. The following variables were evaluated: plant height; pseudostem perimeter; number of emitted suckers and number live leaves, during flowering and at harvest; weight of the bunch and the hands; number of hands and fruits; weight of the second hand; weight, length and diameter of the fruit, in two cycles of production. The plants, considered the basic units, were combined to form various sizes of plots. The data were submitted to the analysis of variance in the hierarchical model. Plot size was estimated by the methods of maximum curvature, modified maximum curvature and comparison of variances. Heterogeneity index of the soil and the detectable difference among treatments mean were determined. The variability increased between cycles with reflexes in the estimates of the plot sizes, which varied with the method used, the variable evaluated and the production cycle. The modified maximum curvature method presents more adjusted estimates. Plots with six basic units $\left(36 \mathrm{~m}^{2}\right)$ are appropriate to evaluate with precision the phenotypic descriptors in the bananas.
\end{abstract}

Index terms: Musa spp., agricultural statistics, morphology, production.

\section{Introdução}

A banana para consumo in natura foi a fruta mais produzida no mundo em 2006 e, em conjunto com plátanos (bananas de cozinhar e fritar) cultivados em 118 países, ocupa área total de 9,61 milhões de hectares, com produção de 104,72 milhões de toneladas. Índia, Uganda, Equador, Brasil, China e Filipinas são os principais países produtores (FAO, 2008) e, juntos, representam cerca de $50 \%$ da produção mundial de bananas e plátanos.

No Brasil, ao contrário da bananicultura latinoamericana de exportação, baseada nas cultivares do subgrupo Cavendish, Grande Naine e Williams, utiliza-se maior diversidade de cultivares, com predomínio de 
bananas 'Prata' (Silva et al., 2000). Porém, não existe uma cultivar que seja resistente a todas as pragas e doenças, apresente elevado rendimento, seja precoce, saborosa, de fácil manejo, com longevidade e tempo de prateleira adequados (Daniels, 2000).

O melhoramento genético assume papel crucial no alcance do ideótipo varietal e, para assegurar a recomendação de genótipos geneticamente superiores, a etapa final de avaliação em experimentos de campo requer precisão. Nessa etapa, são estudados caracteres fenotípicos que refletem crescimento, precocidade e produtividade, que são importantes para a identificação e seleção de indivíduos superiores (Silva et al., 1999, 2000), pois, são quantitativos, fáceis de se mensurar, podem estar sob controle poligênico, sofrem influência ambiental e têm importância econômica (Ortiz, 1997).

A determinação do tamanho de parcela e do número de repetições são questões práticas pertinentes ao planejamento experimental. Sua caracterização de forma adequada confere maior precisão, endossa a extrapolação dos resultados, pois, independentemente dos objetivos dos experimentos, o que se procura detectar é a existência de diferenças significativas entre tratamentos testados.

A maioria dos experimentos agrícolas para determinação do tamanho adequado das parcelas, com diferentes culturas (Vallejo \& Mendoza, 1992; Ortiz, 1995; Viana et al., 2002; Henriques Neto et al., 2004), é realizada com ensaios de uniformidade ou em branco (ensaios conduzidos com um único tratamento), a partir dos quais são calculados a variância e o coeficiente de variação para diferentes dimensões de parcelas avaliadas. Além disso, o tamanho da parcela pode, também, ser estimado pelo uso de experimentos delineados.

Adefinição donúmero de plantas úteis porparcela,em experimentos de avaliação de genótipos de bananeira, apresenta caráter empírico, baseada na experiência do pesquisador. Por exemplo: uma planta por parcela (Silva et al., 2000), seis plantas (Donato et al., 2006), 12 plantas (Pereira et al., 2002), 16 plantas (Oliveira et al., 2007) e 25 plantas (Leite et al., 2003).

A discussão acerca de estimativas de tamanho de parcelas experimentais, para diferentes cultivos, é bastante extensa e se estende da década de 1930 até o presente. Entretanto, para a cultura da bananeira, embora não sejam encontrados trabalhos realizados no Brasil, Genizi et al. (1980), Ortiz (1995), Nokoe \& Ortiz
(1998) e Speijer et al. (1998) empreenderam estudos de estimativas de tamanho de parcela no exterior.

Apesar disto, mesmo ao se fixar determinada espécie, o tamanho ideal da parcela pode variar com o solo, características avaliadas, local do ensaio, época da avaliação, recursos e práticas de manejo no local de experimentação e método de estimativa. Adicionalmente, aumentos de produtividade, como conseqüência da elevada evolução tecnológica e de melhoramento genético, tendem a ser de pequena magnitude.

Este trabalho objetivou estimar o tamanho adequado de parcelas experimentais, para avaliação de descritores fenotípicos relevantes para a caracterização de genótipos de bananeira (Musa spp.).

\section{Material e Métodos}

O experimento foi conduzido entre setembro de 2004 e setembro de 2006, em Latossolo Vermelho-Amarelo distrófico típico A fraco, com textura média fase caatinga hipoxerófila, relevo plano a suave ondulado, na área experimental da Escola Agrotécnica Federal Antônio José Teixeira, Município de Guanambi, Sudoeste da Bahia, a $14^{\circ} 13^{\prime} 30^{\prime \prime} \mathrm{S}, 42^{\circ} 46^{\prime} 53^{\prime \prime} \mathrm{W}$, à altitude de $525 \mathrm{~m}$, com média anual de precipitação $663,69 \mathrm{~mm}$ e temperatura média de $26^{\circ} \mathrm{C}$.

$\mathrm{Na}$ instalação do experimento, foram utilizadas mudas micropropagadas e sistema de irrigação por aspersão convencional fixo, com aspersores subcopa. A implantação e os tratos culturais e fitossanitários seguiram as recomendações para a cultura, e as adubações foram baseadas em análises de solo e de folha.

$\mathrm{O}$ experimento constituiu-se de um ensaio de uniformidade com a cultivar Tropical (YB42-21), híbrido tetraplóide (AAAB), derivado da 'Yangambi' número 02 , resistente à sigatoka-amarela e tolerante ao mal-do-panamá, com frutos tipo maçã, gerado pela Embrapa Mandioca e Fruticultura Tropical. A área útil do experimento foi formada por nove fileiras de 40 plantas cada, no espaçamento $3 \times 2 \mathrm{~m}$, com total de 360 plantas e $2.160 \mathrm{~m}^{2}$.

Nas avaliações, considerou-se cada planta, devidamente identificada na linha e na coluna, como uma unidade básica (UB), área de $6 \mathrm{~m}^{2}$, no total de 360 UBs. As unidades básicas foram agrupadas em 23 modos distintos, tendo-se considerado somente os 
agrupamentos de unidades básicas que originavam parcelas capazes de utilizar cem por cento da área experimental.

Foram mensurados os descritores fenotípicos vegetativos: altura da planta, perímetro do pseudocaule, número de folhas vivas no florescimento e na colheita e número de filhos emitidos; e de rendimento: peso do cacho e das pencas, número de pencas e de frutos, peso da segunda penca, peso, comprimento e diâmetro do fruto, em dois ciclos de produção (mãe e filho), conforme Silva et al. (1999).

Os dados foram submetidos à análise de variância, em classificação hierárquica, tendo-se simulado experimentos em parcelas subdivididas (Vallejo \& Mendoza, 1992; Ortiz, 1995). Para cada característica avaliada, foram considerados os efeitos de bloco (B), parcelas $(\mathrm{P}) / \mathrm{B}$, subparcelas $(\mathrm{S}) / \mathrm{P} / \mathrm{B}$, fileiras $(\mathrm{F}) / \mathrm{S} / \mathrm{P} / \mathrm{B}$, e plantas (Pln)/F/S/P/B (Ortiz, 1995). Assim, foram obtidas parcelas com 1, 5, 15, 45 e 180 UBs, a partir da divisão do conjunto (360 plantas úteis) em dois blocos de 180 plantas; da subdivisão de cada bloco em quatro parcelas de 45 plantas; e da subdivisão de cada parcela em três subparcelas de três fileiras, com cinco plantas cada.

O tamanho da parcela foi estimado pelos métodos da máxima curvatura (Federer, 1963), máxima curvatura modificado (Meier \& Lessman, 1971) e comparação de variâncias (Vallejo \& Mendozza, 1992). Determinaramse, ainda, a diferença detectável entre médias de tratamentos (d), pela equação de Hatheway (1961), e o índice de heterogeneidade (b) de Smith (1938).

Nos cálculos do índice de heterogeneidade do solo e do coeficiente de variação, para estimativa de tamanho de parcela, pelos métodos da máxima curvatura e da máxima curvatura modificado, as características avaliadas de UBs adjacentes foram combinadas para formar diferentes tipos de parcelas. Esses cálculos foram executados com rotinas desenvolvidas pelo próprio autor, em ferramenta computacional do tipo planilhas eletrônicas, em formato Microsoft Excel.

Foram calculados os coeficientes de variação (CV) dos diferentes caracteres avaliados nos dois ciclos de produção, em relação aos vários tamanhos de parcelas pré-estabelecidos, tendo-se obtido uma curva utilizada para determinação do tamanho de parcela, com o ponto de máxima curvatura localizado por inspeção visual. Considerou-se, como tamanho ótimo de parcela, o valor da abscissa correspondente ao ponto na curva onde ocorre a maior taxa de mudança do $\mathrm{CV}$, em resposta ao aumento do tamanho da área (Le Clerg, 1967). Na construção dos gráficos e obtenção das curvas, utilizou-se ferramenta computacional, tipo planilha eletrônica, formato Microsoft Excel, unindose os pontos com segmento de reta (Ortiz, 1995; Viana et al., 2002; Henriques Neto et al., 2004).

No método da máxima curvatura modificado, a relação entre CV e tamanho da parcela é representada por uma equação de regressão do tipo $\mathrm{y}=\mathrm{a} / \mathrm{x}^{\mathrm{b}}$, em que: y representa o CV e x o correspondente tamanho da parcela em UB. Adotou-se, para o método da máxima curvatura modificado, a função matemática $\mathrm{CV}=\mathrm{a} \mathrm{X}^{\mathrm{b}}$, em que o valor da abscissa correspondente ao ponto da máxima curvatura $\mathrm{X}_{\mathrm{MC}}$ é dado pela fórmula: $X_{\mathrm{MC}}=\left[\mathrm{a}^{2} \mathrm{~b}^{2}(2 \mathrm{~b}+1) /(\mathrm{b}-2)\right]^{1 /(2 \mathrm{~b}+2)}$, em que: a é a constante de regressão (intercepto); e b é o coeficiente de regressão (inclinação), conforme Meier \& Lessman (1971) e Henriques Neto et al. (2004).

As estimativas das variâncias originais $\left(\hat{V}_{i}\right)$ dos tamanhos de parcelas, obtidas por meio da análise de variância em modelo hierárquico, foram corrigidas e reduzidas em relação à menor unidade de classificação hierárquica. Após esses procedimentos, aplicaram-se consecutivos testes de Bartlett, a 5\% de probabilidade, para testar a homogeneidade das variâncias (Gomez \& Gomez, 1984). Excluiu-se de cada teste a menor parcela com variância significativamente diferente e identificou-se, como ideal, o menor tamanho de parcela do grupo de parcelas de diferentes tamanhos, com variâncias estatisticamente similares.

A equação de Hatheway (1961) foi utilizada para se estimar a diferença detectável entre médias de tratamentos $(\mathrm{d}): \mathrm{d}=\left[2\left(\mathrm{t}_{1}+\mathrm{t}_{2}\right)^{2} \mathrm{CV}^{2} / \mathrm{rx}^{\mathrm{b}}\right]^{0,5}$, em que: $\mathrm{d}$ é a diferença a ser detectada, medida em percentagem da média, para simulação de diferentes tamanhos de parcelas adequados às condições da pesquisa; $\mathrm{t}_{1}$ é $\mathrm{o}$ valor crítico da distribuição de Student, à probabilidade $\alpha_{1} ; t_{2}$ é o valor crítico da distribuição de Student à probabilidade $\alpha_{2}=2(1-\mathrm{P})$, em que P é a probabilidade selecionada para se obter resultado significativo; $\mathrm{CV}^{2}$ é o quadrado do CV (\%) de parcelas de uma UB de tamanho; $r$ é o número de repetições; $X$ é o tamanho de parcela para um dado número de UBs; e b é o coeficiente ou índice de heterogeneidade de Smith.

Para a estimativa de $\mathrm{d}$, foram considerados o $\mathrm{CV}$ e o índice b, em relação a cada variável, nos dois ciclos de produção da bananeira, e quanto aos 
tamanhos de parcela de 1 a 24 UBs $\left(6\right.$ a $\left.144 \mathrm{~m}^{2}\right)$, por representarem tamanhos utilizados na prática, em avaliação de genótipos, para experimentos com 6 tratamentos, com 3 e 6 repetições, com os níveis de precisão $\alpha_{1}=5,0 \%$ e $\alpha_{2}=2(1-\mathrm{P})$, com $\mathrm{P}=0,80$ ( $80 \%$ de probabilidade), em delineamento em blocos casualizados.

Para se estimar o índice $\mathrm{b}$ de heterogeneidade do solo foi feito o ajuste das equações de regressão linear - entre o logaritmo da variância de cada característica nos dois ciclos de produção da bananeira, para cada tamanho de parcela pré-estabelecido e o logaritmo do respectivo tamanho da parcela -, expresso em UBs: $\log \mathrm{V}_{\mathrm{x}}=\log \mathrm{V}_{1}-\mathrm{b} \log \mathrm{x}$, obtida pela linearização da equação de Smith (1938) $\mathrm{V}_{\mathrm{x}}=\mathrm{V}_{1} / \mathrm{x}^{\mathrm{b}}$, em que: $\mathrm{V}_{\mathrm{x}}$ é a variância entre parcelas de $\mathrm{x} U B s$; $V_{1}$ é a variância entre parcelas de tamanho igual a uma UB; b é o índice de heterogeneidade do solo; e x é o tamanho da parcela em unidades básicas.

\section{Resultados e Discussão}

Nas características avaliadas entre os ciclos de produção de bananeira 'Tropical', foram observadas elevações quanto à altura da planta (de 301 para $383 \mathrm{~cm}$ ), perímetro do pseudocaule (de 80 para $92,19 \mathrm{~cm}$ ), número de pencas (de 5 para 7) e número de frutos (de 80 para 120). Em estudo com a mesma cultivar, Lima et al. (2005) obtiveram peso do cacho de 12 e de $16 \mathrm{~kg}$, enquanto no presente trabalho a média foi de 14,32 e de $14,85 \mathrm{~kg}$, para o primeiro e o segundo ciclo de produção, respectivamente. O que contribuiu para ausência de incrementos entre os ciclos, quanto a esta característica, foram os decréscimos observados em peso, comprimento e diâmetro do fruto de $158,07 \mathrm{~g}$ para $103,74 \mathrm{~g}$, $15,88 \mathrm{~cm}$ para $14,39 \mathrm{~cm}$ e de $40,77 \mathrm{~mm}$ para $34,13 \mathrm{~mm}$, respectivamente.

Osvalores dos CV foraminversamenteproporcionais ao tamanho da parcela, variaram com o tipo de característica avaliada e com o ciclo de produção (Tabela 1), semelhantemente a Nokoe \& Ortiz (1998).

Tabela 1. Estimativas de coeficientes de variação (\%), em função do tamanho de parcela em unidades básicas (UBs), de características fenotípicas avaliadas no primeiro e segundo ciclo de produção em bananeira 'Tropical', em Guanambi, BA, em 2005 e 2006.

\begin{tabular}{|c|c|c|c|c|c|c|c|}
\hline \multirow[t]{2}{*}{ Variável } & \multirow[t]{2}{*}{ Ciclo } & \multicolumn{5}{|c|}{ Tamanho da parcela (UB) } & \multirow[t]{2}{*}{ CV (\%) } \\
\hline & & 180 & 45 & 15 & 5 & 1 & \\
\hline \multirow[t]{2}{*}{ Altura da planta } & $1^{\circ}$ & 1,85 & 1,89 & 2,17 & 3,24 & 4,93 & 4,17 \\
\hline & $2^{\underline{o}}$ & 3,18 & 3,29 & 3,97 & 4,48 & 6,30 & 4,97 \\
\hline \multirow[t]{2}{*}{ Perímetro do pseudocaule } & $1^{\mathrm{O}}$ & 1,75 & 1,88 & 2,12 & 2,92 & 5,18 & 4,78 \\
\hline & $2^{\underline{0}}$ & 3,74 & 3,72 & 4,47 & 5,11 & 7,60 & 6,31 \\
\hline \multirow{2}{*}{ Número de folhas vivas no florescimento } & $1^{\underline{o}}$ & 2,93 & 2,98 & 4,45 & 6,35 & 11,92 & 11,28 \\
\hline & $2^{-}$ & 2,08 & 2,36 & 3,90 & 5,91 & 11,48 & 11,00 \\
\hline \multirow{2}{*}{ Número de filhos emitidos } & $1^{\mathrm{o}}$ & 3,16 & 4,99 & 7,55 & 11,83 & 23,66 & 22,91 \\
\hline & $2^{\mathrm{o}}$ & 0,91 & 2,64 & 11,07 & 16,33 & 31,47 & 30,09 \\
\hline \multirow{2}{*}{ Número de folhas vivas na colheita } & $1^{\underline{o}}$ & 2,69 & 3,59 & 4,34 & 6,94 & 13,58 & 13,06 \\
\hline & $2^{\mathrm{o}}$ & 4,45 & 4,85 & 6,06 & 9,05 & 16,59 & 15,56 \\
\hline \multirow[t]{2}{*}{ Peso do cacho } & $1^{\circ}$ & 1,99 & 4,68 & 5,65 & 8,19 & 15,63 & 14,89 \\
\hline & $2^{\underline{e}}$ & 5,57 & 5,66 & 7,18 & 10,07 & 18,65 & 17,56 \\
\hline \multirow{2}{*}{ Peso das pencas } & $1^{\mathrm{o}}$ & 1,66 & 4,67 & 5,90 & 8,76 & 16,40 & 15,51 \\
\hline & $2^{\underline{o}}$ & 5,98 & 5,89 & 7,60 & 10,75 & 19,92 & 18,76 \\
\hline \multirow[t]{2}{*}{ Número de pencas } & $1^{\underline{o}}$ & 0,83 & 1,61 & 2,76 & 4,21 & 10,04 & 10,18 \\
\hline & $2^{\underline{o}}$ & 1,05 & 2,24 & 3,38 & 5,40 & 10,73 & 10,37 \\
\hline \multirow[t]{2}{*}{ Número de frutos } & $1^{\circ}$ & 1,68 & 2,36 & 4,43 & 6,95 & 13,53 & 12,98 \\
\hline & $2^{\underline{o}}$ & 3,29 & 4,02 & 5,50 & 8,04 & 16,45 & 16,04 \\
\hline \multirow[t]{2}{*}{ Peso da segunda penca } & $1^{\underline{o}}$ & 1,34 & 4,13 & 5,82 & 8,37 & 15,93 & 15,16 \\
\hline & $2^{\underline{o}}$ & 3,28 & 5,63 & 6,58 & 10,92 & 19,64 & 18,27 \\
\hline \multirow[t]{2}{*}{ Peso do fruto } & $1^{\mathrm{o}}$ & 1,09 & 2,71 & 4,75 & 7,03 & 14,43 & 14,09 \\
\hline & $2^{-}$ & 3,73 & 4,25 & 6,16 & 10,72 & 19,69 & 18,48 \\
\hline \multirow[t]{2}{*}{ Comprimento do fruto } & $1^{\mathrm{O}}$ & 0,72 & 2,53 & 3,67 & 5,71 & 10,22 & 9,49 \\
\hline & $2^{\underline{9}}$ & 1,05 & 1,99 & 2,60 & 5,48 & 10,91 & 10,54 \\
\hline \multirow[t]{2}{*}{ Diâmetro do fruto } & $1^{\mathrm{o}}$ & 0,75 & 1,16 & 2,00 & 3,11 & 5,98 & 5,71 \\
\hline & $2^{\underline{9}}$ & 1,52 & 1,68 & 2,43 & 4,11 & 7,04 & 6,40 \\
\hline
\end{tabular}


Alterações nos CVs entre os ciclos da planta-mãe e do filho são esperadas (Ortiz, 1995), particularmente, quando se utilizam mudas micropropagadas (mesma idade), o que confere maior uniformidade no primeiro ciclo, em comparação ao ciclo do seguidor (mais sujeito às condições ambientais e de manejo).

$\mathrm{O}$ índice $\mathrm{b}$ de heterogeneidade do solo variou com a característica avaliada e com o ciclo de produção, similarmente a Genizi et al. (1980). Os valores para o primeiro e o segundo ciclo foram: 0,4639 e 0,3170 - altura da planta; 0,5440 e 0,3254 - perímetro do pseudocaule; 0,5814 e 0,7020 - número de folhas vivas no florescimento; 0,7702 e 1,1271 - número de filhos; 0,7017 e 0,6123 - número de folhas vivas na colheita; 0,7414 e 0,5554 - peso do cacho; 0,7868 e 0,5567 - peso das pencas; 0,8104 e 0,9214 - número de pencas; 0,7349 e 0,9411 - número de frutos; 08509 e 0,8651 - peso da segunda penca; 0,8047 e 0,6667 - peso do fruto; 0,9651 e 0,6442 - comprimento do fruto; e 0,7748 e 0,6098 - diâmetro do fruto.

Valores superiores a 0,70 denotam alta variabilidade (pouca correlação entre unidades adjacentes), enquanto valores entre 0,2 e 0,7 significam variabilidade intermediária. Embora as estimativas de b normalmente variem entre 0 e 1 , o valor acima da unidade, como encontrado quanto a número de filhos emitidos, também foi registrado em peso do cacho por Ortiz (1995).

A bananeira é propagada vegetativamente e apresenta pouca variabilidade genética, embora exiba variação somaclonal, principalmente se a micropropagação é realizada sem os devidos cuidados, provavelmente em razão da instabilidade mitótica e da mutação (Silva et al., 2002). Infere-se que o grau de variabilidade, refletido pelo índice b no presente trabalho, é mais conseqüência do solo e de outros fatores que afetam a heterogeneidade experimental (erros procedentes das técnicas de plantio, práticas culturais, colheita e das mensurações), o que é corroborado pelos maiores valores de b $(0,7702$ e 1,1271), em relação ao número de filhos emitidos, que reflete a prática cultural denominada desbrota ou desbaste.

Viana et al. (2002) e Henriques Neto et al. (2004) apontam, como limitações inerentes ao método da máxima curvatura, a dependência da escala e a dificuldade de identificação do ponto de máxima curvatura, correspondente ao tamanho ótimo da unidade experimental, o que foi constatado neste trabalho (Figura 1). Conseqüentemente, os tamanhos ótimos de parcelas, quanto às características avaliadas, foram estimados com escala menor, tendo-se considerado apenas a região de maior curvatura (1 a $20 \mathrm{UBs}$ ).

Em relação ao método da máxima curvatura, o tamanho adequado de parcela, no primeiro ciclo de produção (Figura $1 \mathrm{~A} \mathrm{e} \mathrm{C}$ ), variou de 5 UBs $\left(30 \mathrm{~m}^{2}\right)$ a 9 UBs $\left(54 \mathrm{~m}^{2}\right)$, enquanto no segundo ciclo de produção, o valor estimado convergiu para 9 UBs $\left(54 \mathrm{~m}^{2}\right)$, independentemente da variável avaliada (Figura $1 \mathrm{~B}$ e D).

Em experimentos com bananeira cultivar Valery (AAA), quanto à característica peso do cacho, Ortiz (1995) encontrou tamanho ótimo de parcela de $120 \mathrm{~m}^{2}$ (20 plantas), em cultivo em consórcio, e de $240 \mathrm{~m}^{2}$ (40 plantas) em cultivo solteiro, valores superiores aos estimados neste trabalho. Isso pode ser atribuído à escala utilizada pelo autor, com apenas cinco tamanhos de parcela pré-definidos (1, 5, 20, 40 e $80 \mathrm{UBs})$. Embora também possa ter havido influência do maior valor do CV da parcela unitária quanto ao peso do cacho (35\%), observado no trabalho de Ortiz (1995), em comparação aos 15,63 e 18,65\% obtidos no presente trabalho, Henriques Neto et al. (2004) argumentam que o tamanho da parcela estimado pela máxima curvatura não depende diretamente da magnitude do $\mathrm{CV}$, mas do comportamento deste índice em resposta aos aumentos no tamanho da unidade experimental.

No método da máxima curvatura modificado, a determinação algébrica do ponto de máxima curvatura $\mathrm{X}_{\mathrm{MC}}$ resulta em maior precisão (Viana et al., 2002), pois a relação entre $\mathrm{CV}$ e tamanho de parcela é explicada por meio de equação de regressão, porém, resulta em valores não necessariamente inteiros (Figuras 2, 3 e 4). No presente trabalho, como a UB é a unidade natural (uma planta), arredondaram-se os valores calculados para o inteiro subseqüente. A opção de se arredondar o valor para cima decorre do fato de esse método, de modo geral, estimar valores pequenos de tamanhos de parcela; pode ocorrer, ainda, decréscimo nos valores do $\mathrm{CV}$, com o aumento do tamanho da parcela, na região imediatamente superior ao ponto de máxima curvatura (Henriques Neto et al., 2003).

Os tamanhos de parcela estimados foram de sete plantas $\left(42 \mathrm{~m}^{2}\right)$ e cinco plantas $\left(30 \mathrm{~m}^{2}\right)$, no segundo e primeiro ciclo, em relação a número de filhos emitidos; quatro plantas $\left(24 \mathrm{~m}^{2}\right)$ quanto a peso do cacho e das pencas (primeiro ciclo), número de frutos (segundo ciclo), peso da segunda penca e do fruto (dois ciclos); 
três plantas $\left(18 \mathrm{~m}^{2}\right)$ quanto a número de frutos (primeiro ciclo), número de folhas vivas no florescimento, peso do cacho e das pencas (segundo ciclo), número de folhas vivas na colheita, número de pencas e comprimento do fruto (dois ciclos); duas plantas $\left(12 \mathrm{~m}^{2}\right)$ em relação ao perímetro do pseudocaule e número de folhas vivas no florescimento (primeiro ciclo) e diâmetro do fruto (dois ciclos); uma planta $\left(6 \mathrm{~m}^{2}\right)$ quanto à altura da planta (dois ciclos) e ao perímetro do pseudocaule (segundo ciclo).

Pela análise da Tabela 1 e das Figuras 2, 3 e 4, observa-se que as estimativas de tamanho de parcela, quanto às características avaliadas, variaram de forma inversa com o CV da parcela unitária (parcela com uma UB) - $\mathrm{CVp}_{1}$, nos dois ciclos de produção. Os valores obtidos foram mais concordantes quanto às características de rendimento, com menor variação nas estimativas do tamanho de parcela, em comparação às características vegetativas, o que se justifica pelo fato de as características de rendimento serem altamente correlacionadas (Sirisena \& Senanayake, 2000; Tenkouano et al., 2002; Lima Neto et al., 2003), apresentarem associação genética e elevada herdabilidade, pois, os caracteres avaliados fazem parte do próprio cacho.

Os dados atestam maior influência do $\mathrm{CV}$ que do índice $\mathrm{b}$ de heterogeneidade do solo, nos tamanhos de parcelas estimados, analogamente ao encontrado por Henriques Neto et al. (2004). Características com valores de $\mathrm{b}$ muito próximos, porém com $\mathrm{CV}$ diferentes, diferiram nos tamanhos de parcelas. Isso pode ser constatado quanto a peso do cacho $\left(b=0,3707\right.$ e $\left.C V p_{1}=15,63 \%\right)$ e diâmetro
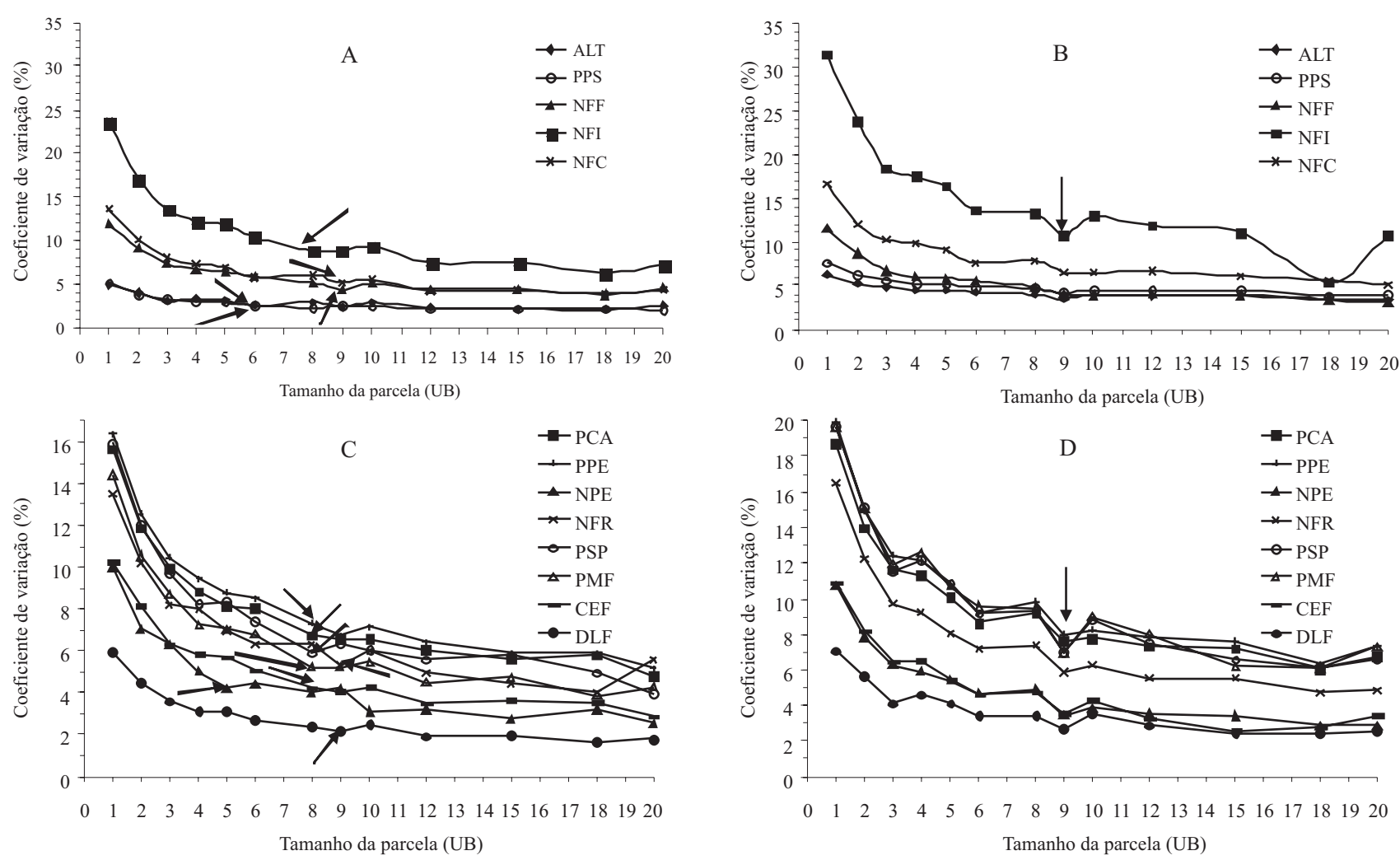

Figura 1. Relação entre coeficiente de variação e tamanho de parcela, em unidades básicas (UB), das características: altura da planta (ALT), perímetro do pseudocaule (PPS), número de folhas vivas no florescimento (NFF), número de filhos emitidos (NFI), número de folhas vivas na colheita (NFC), peso do cacho (PCA), peso das pencas (PPE), número de pencas (NPE), número de frutos (NFR), peso da segunda penca (PSP), peso do fruto (PMF), comprimento do fruto (CEF) e diâmetro do fruto (DLF), avaliadas no primeiro (A e C) e segundo (B e D) ciclo de produção de bananeira 'Tropical', em Guanambi, BA, em 2005 e 2006. As setas indicam o ponto de máxima curvatura (tamanho adequado da parcela). 

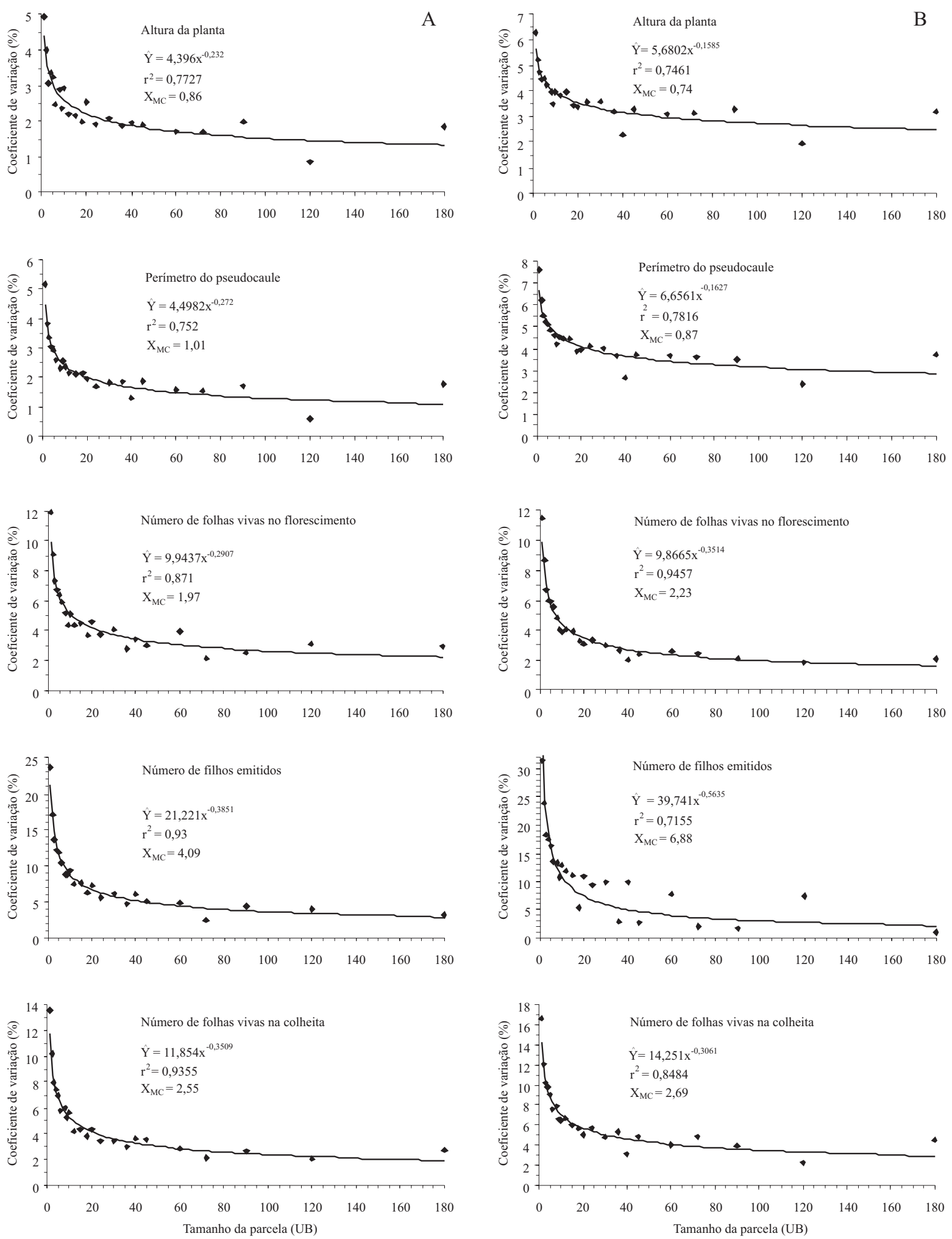

Figura 2. Relação entre coeficiente de variação (CV) e tamanho de parcela, em unidades básicas (UB), e valor da abscissa no ponto de máxima curvatura $\left(\mathrm{X}_{\mathrm{MC}}\right)$, das características vegetativas avaliadas no primeiro (A) e segundo (B) ciclo de produção de bananeira 'Tropical', em Guanambi, BA, em 2005 e 2006. 
do fruto $\left(b=0,3874\right.$ e $\left.\mathrm{CVp}_{1}=5,98 \%\right)$, no primeiro ciclo de produção, com tamanhos de parcela estimados de duas e quatro unidades básicas, respectivamente, e também quanto a peso do fruto $(b=0,3221 \mathrm{e}$ $\left.\mathrm{CVp}_{1}=19,69 \%\right)$ e diâmetro do fruto $(\mathrm{b}=0,3049 \mathrm{e}$ $\mathrm{CVp}_{1}=7,04 \%$ ), no segundo ciclo de produção.
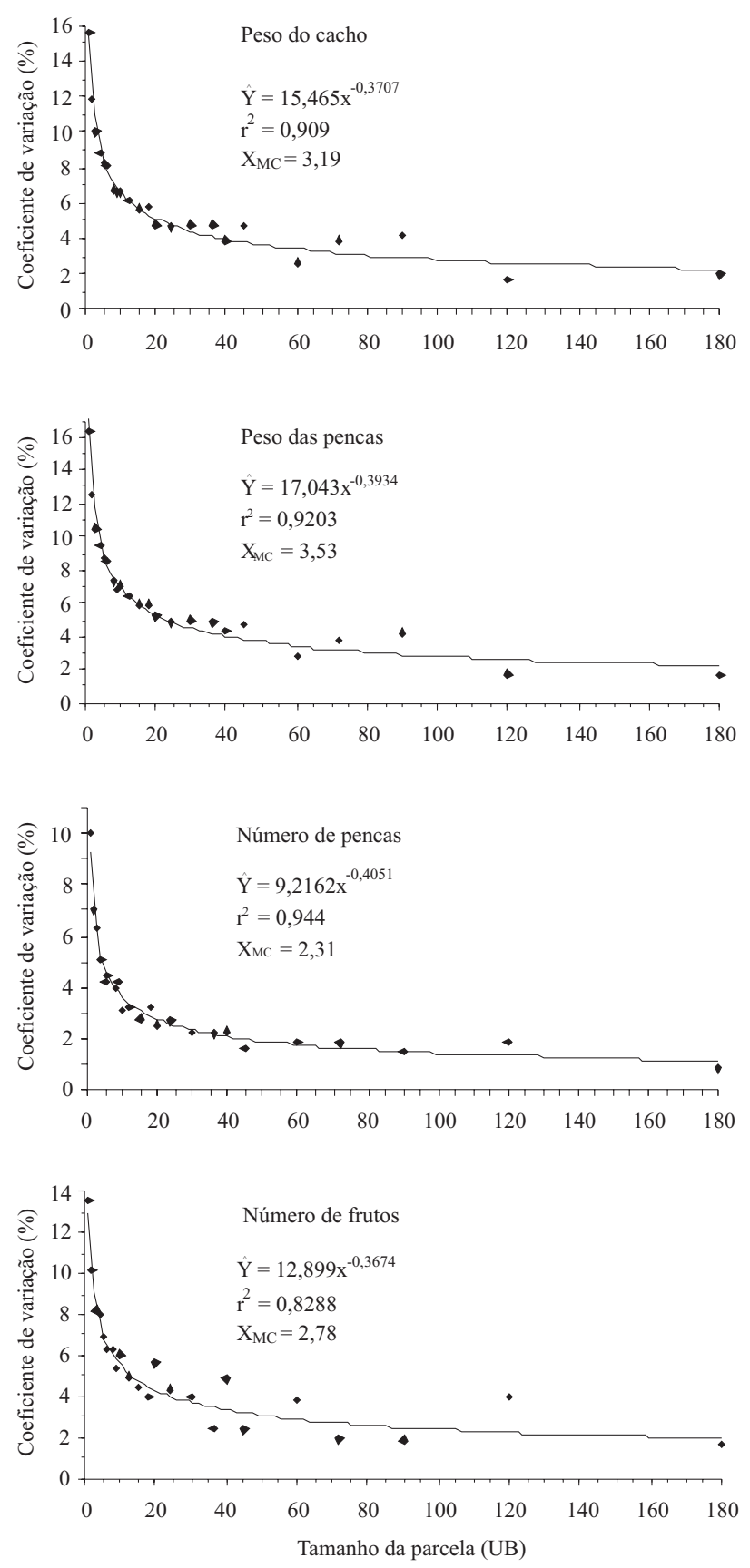

Os resultados ilustram a relação inversa entre tamanho de parcela e sua variância (Tabela 2), pressuposto básico da lei das variâncias de Smith (1938), comprovado por diferentes autores (Hatheway, 1961; Le Clerg, 1967; Vallejo \& Mendoza, 1992; Ortiz, 1995; Viana et al., 2002; Henriques Neto et al., 2004),
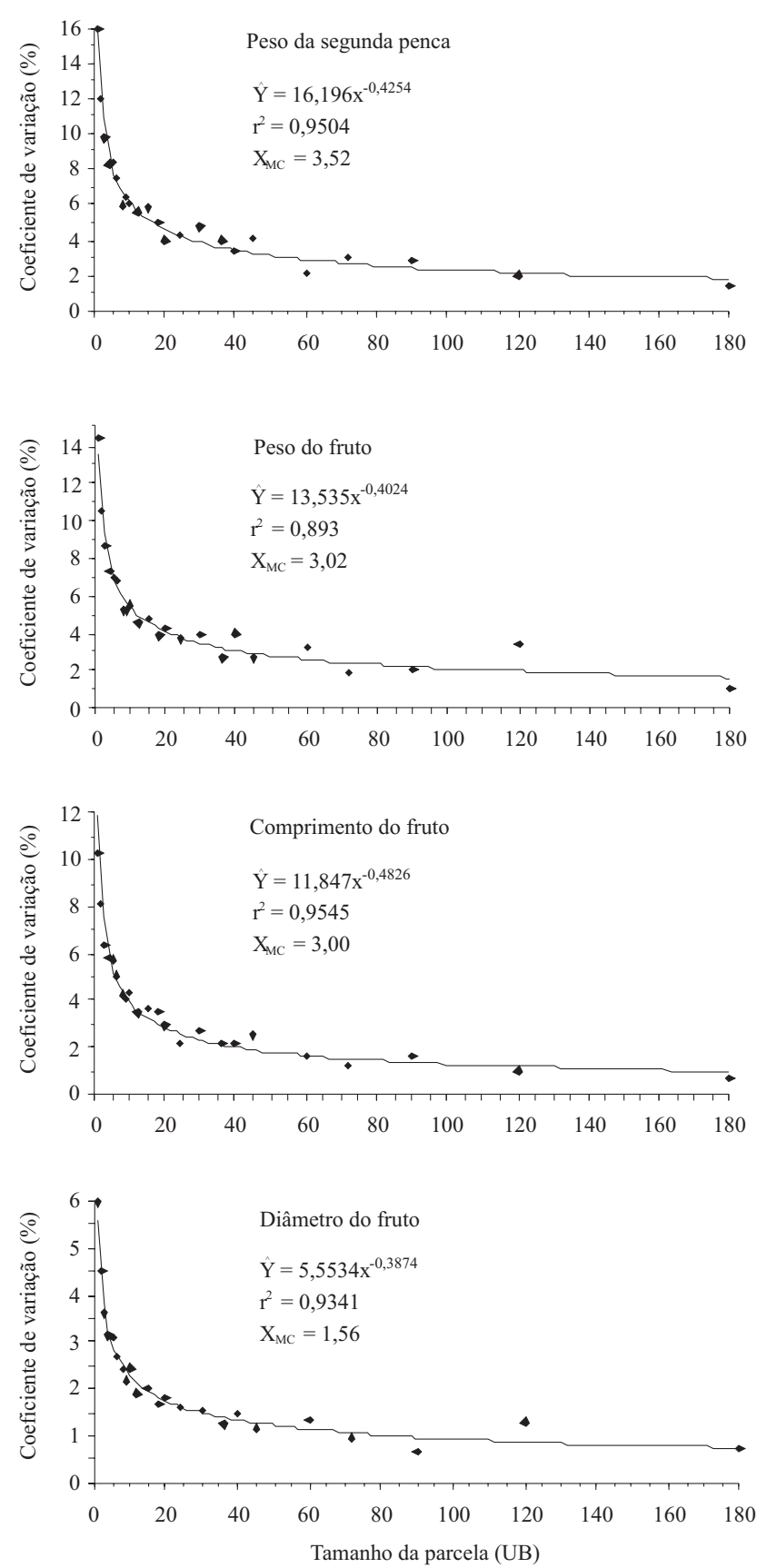

Figura 3. Relação entre coeficiente de variação (CV) e tamanho de parcela, em unidades básicas (UB), e valor da abscissa no ponto de máxima curvatura $\left(\mathrm{X}_{\mathrm{MC}}\right)$, de características de rendimento avaliadas no primeiro ciclo de produção de bananeira 'Tropical', em Guanambi, BA, em 2005. 
pois, as parcelas de tamanho unitário (uma UB) apresentam maior variância da média, em todas as características avaliadas nos dois ciclos de produção, seguida das parcelas de tamanho imediatamente superior.
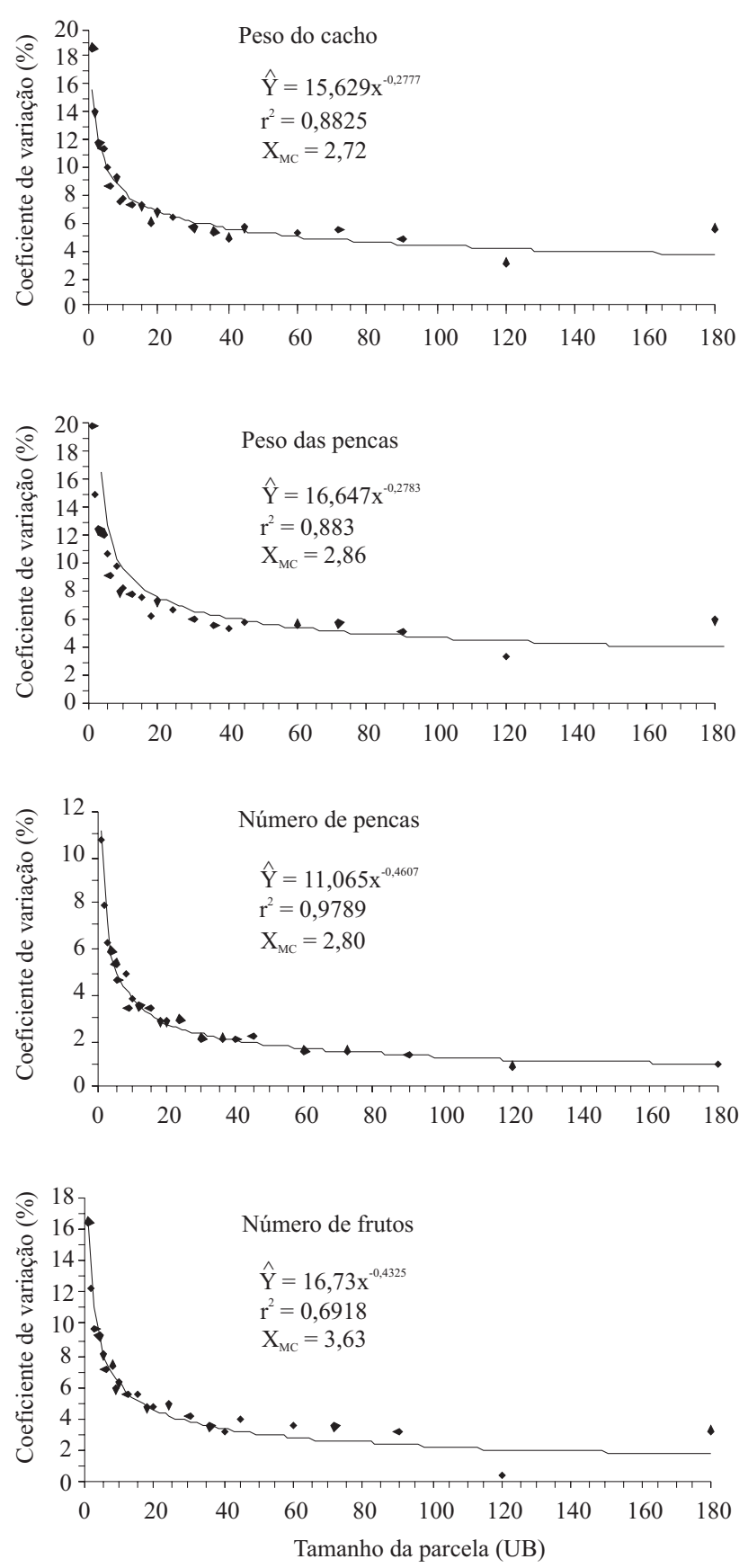

Com a aplicação de testes consecutivos (Bartlett a $5 \%$ ) (Tabela 2), constatou-se a homogeneidade das variâncias das parcelas de 5, 15, 45 e 180 UBs, quanto às seguintes variáveis: altura da planta; perímetro do pseudocaule; número de folhas vivas, no florescimento;
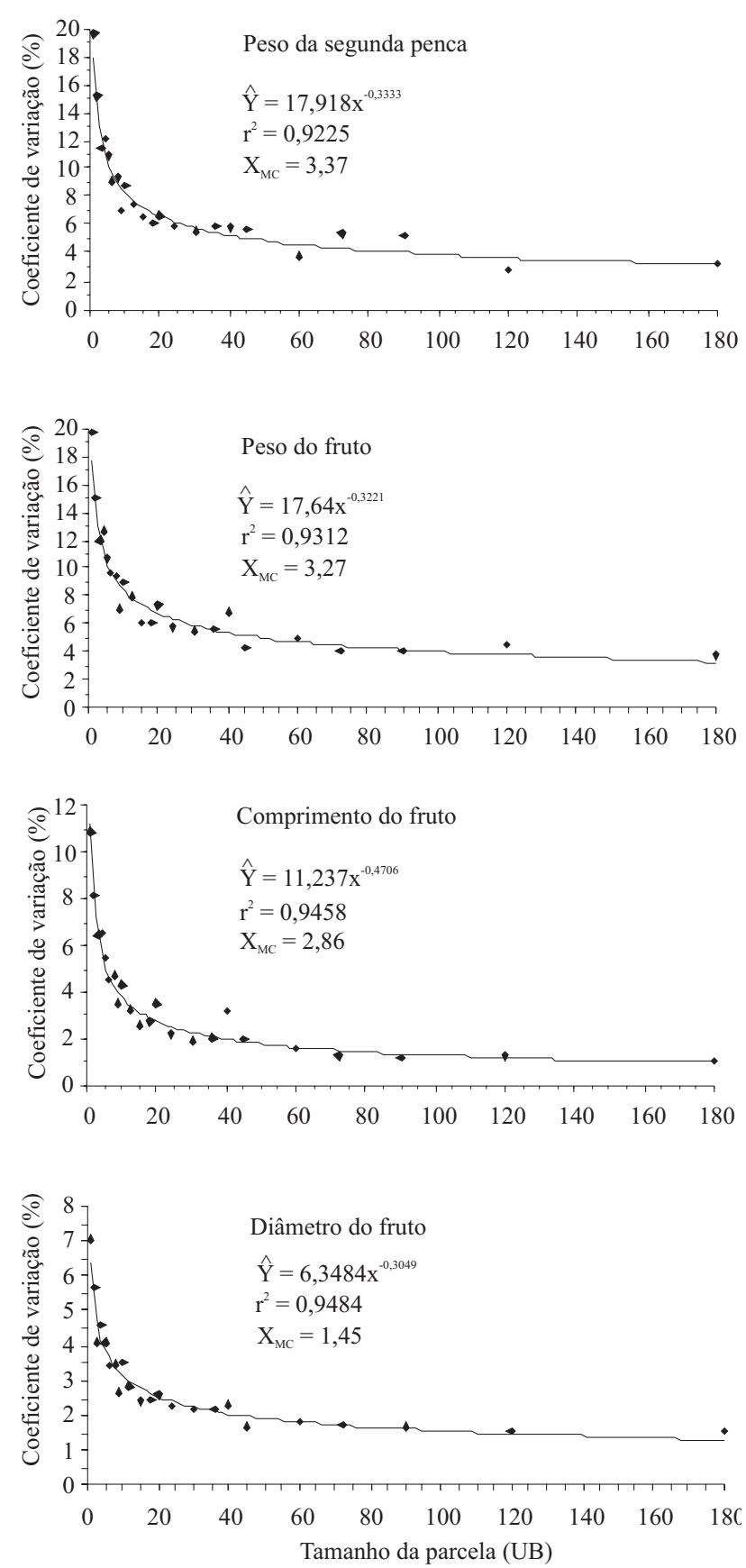

Figura 4. Relação entre coeficiente de variação (CV) e tamanho de parcela, em unidades básicas (UB), e valor da abscissa no ponto de máxima curvatura $\left(\mathrm{X}_{\mathrm{MC}}\right)$, de características de rendimento avaliadas no segundo ciclo de produção de bananeira 'Tropical', em Guanambi, BA, em 2006. 
peso do cacho das pencas, nos dois ciclos de produção; número de pencas, peso da segunda penca e do fruto, no primeiro ciclo; número de folhas vivas na colheita e de frutos, segundo ciclo. Nesses casos, 5 UBs $\left(30 \mathrm{~m}^{2}\right)$ é o tamanho adequado de parcela, enquanto em relação a número de folhas vivas na colheita, número de filhos emitidos e de frutos (primeiro ciclo), número de pencas, peso da segunda penca e do fruto (segundo ciclo), comprimento e diâmetro do fruto (dois ciclos de produção), o tamanho ótimo é de 15 UBs $\left(90 \mathrm{~m}^{2}\right)$; quanto ao número de filhos emitidos no segundo ciclo, o tamanho estimado é de $45 \mathrm{UBs}\left(270 \mathrm{~m}^{2}\right)$. Por sua vez, o tamanho de parcela estimado pelo método da comparação de variâncias quanto à característica peso do cacho, nos dois ciclos de produção, assemelha-se ao encontrado por Ortiz (1995).

O aumento do número de repetições de três para seis, para todas as características avaliadas, foi eficiente em aumentar a precisão experimental e reduzir os valores de $\mathrm{d}$, diferença detectável entre médias de tratamentos (Tabela 3). Observaram-se, também, reduções consideráveis nos valores de $\mathrm{d}$ com o aumento na área das parcelas - que ocorrem de forma geral para parcelas com até 6 UBs -, a partir do qual, o aumento de precisão torna-se pequeno com incrementos adicionais na área das parcelas, similarmente ao observado por Henriques Neto et al. (2004). Esse comportamento assemelha-se ao verificado na relação entre $\mathrm{CV}$ e tamanho da parcela, como esperado, pois expressa a relação inversa entre variância e tamanho da parcela (Smith, 1938; Hatheway, 1961; Lê Clerg, 1967).

Os resultados encontrados no presente trabalho facultam assegurar que parcelas de 1 a 6 UBs, a depender da característica avaliada, mesmo para a de maior variabilidade (número de filhos emitidos), permitem detectar diferenças de $15 \%$ da média, com apenas três repetições. Parcelas com 4 UBs possibilitam a mesma precisão experimental, com o uso de seis repetições. Esses resultados levam a inferir que parcelas com 16 plantas (Oliveira et al., 2007) e 25 plantas (Leite et al., 2003), podem ser desnecessárias, por aumentarem os custos pela maior área e material experimental utilizados, sem aumentos essenciais na precisão experimental.

Diferenças de $15 \%$ entre médias de tratamentos, quanto ao peso do cacho - com 2 repetições, 30 tratamentos e parcelas de $10 \mathrm{UBs}$, e com 6 repetições, 10 tratamentos e parcelas de 5 UBs foram obtidas por Ortiz (1995), enquanto Genizi et al. (1980) detectaram diferenças entre médias de tratamentos de $5 \%$ com parcelas de 4 UBs, cinco tratamentos e cinco repetições. A diferença a ser detectada entre duas médias de tratamentos será significativa, quando o seu valor for maior que o $\mathrm{CV}$ inerente à característica avaliada. De posse da Tabela 3, pode-se obter a combinação entre tamanho de parcela e número de repetições, para auferir o nível de precisão requerido. A decisão é conseqüência

Tabela 2. Estimativas das variâncias reduzidas para uma unidade básica, do ensaio de uniformidade com bananeira 'Tropical', das características fenotípicas avaliadas em dois ciclos de produção, em diferentes tamanhos de parcela em unidades básicas (UB), em Guanambi, BA, em 2005 e $2006^{(1)}$.

\begin{tabular}{|c|c|c|c|c|c|c|c|c|c|c|}
\hline \multirow[t]{2}{*}{ Características fenotípicas } & \multicolumn{5}{|c|}{ Tamanho da parcela (UB) } & \multicolumn{5}{|c|}{ Tamanho da parcela (UB) } \\
\hline & 1 & 5 & 15 & 45 & 180 & 1 & 5 & 15 & 45 & 180 \\
\hline & & & $\mathrm{clc}$ & & - & & & 2 & & \\
\hline Alt & $221,2254 a$ & $b$ & $42,6185 b$ & $32,3797 b$ & 30,985 & 2,376 & 294 & 230,6 & $58,9030 b$ & $148,0156 b$ \\
\hline $\mathrm{Pe}$ & & & & & & & & & & \\
\hline & to $2,2971 \mathrm{a}$ & $0,6531 \mathrm{~b}$ & $0,3208 b$ & $0,1436 b$ & $0,1393 b$ & & $0,5434 \mathrm{~b}$ & & 0,0 & \\
\hline Núr & $0,9978 \mathrm{a}$ & $0,2496 b$ & $0,1015 \mathrm{c}$ & $0,0444 \mathrm{c}$ & & & $0,3175 b$ & & $0,0083 \mathrm{c}$ & \\
\hline Folh & 1466 & 0,3 & $8 \mathrm{c}$ & 0,10 & $4 \mathrm{c}$ & $1 \mathrm{a}$ & $21 b$ & $3 b$ & $0,1761 b$ & $32 b$ \\
\hline Peso & . & $1,3755 b$ & $0,6551 \mathrm{~b}$ & $0,4493 b$ & $0,0816 b$ & $7,6644 a$ & $56 b$ & $1,1350 \mathrm{~b}$ & $0,7062 b$ & $0,6835 b$ \\
\hline & $\mathrm{a}$ & $1,2215 b$ & $0,5547 \mathrm{~b}$ & $0,3471 b$ & $0,0440 \mathrm{~b}$ & 6,4 & $1,8907 \mathrm{~b}$ & $0,9466 b$ & $0,5675 b$ & 0,58 \\
\hline Núı & $0,2751 \mathrm{a}$ & $0,0484 \mathrm{~b}$ & $0,0208 \mathrm{~b}$ & $0,0071 b$ & $0,0019 b$ & $3 a$ & $0,1464 b$ & $75 \mathrm{c}$ & $3 c$ & $0,0056 \mathrm{c}$ \\
\hline Núm & $17,5066 \mathrm{a}$ & $31,0357 \mathrm{~b}$ & $12,6004 c$ & $3,5885 \mathrm{c}$ & $1,8156 \mathrm{c}$ & $89,0384 a$ & $93,0039 b$ & $43,5316 b$ & $23,1867 b$ & $15,5558 \mathrm{~b}$ \\
\hline & & $0,0501 \mathrm{~b}$ & & $0,0122 b$ & & $0,1577 \mathrm{a}$ & $0,0487 \mathrm{~b}$ & $0,0177 \mathrm{c}$ & $0,0129 \mathrm{c}$ & $0,0044 \mathrm{c}$ \\
\hline Peso & $520,2375 a$ & $123,4785 b$ & $56,4632 b$ & $18,4129 b$ & $2,9741 \mathrm{~b}$ & $417,4302 a$ & $123,7348 b$ & 40,8 & $19,4503 \mathrm{c}$ & $14,9422 \mathrm{c}$ \\
\hline Com & $2,6347 a$ & $0,8210 \mathrm{~b}$ & $0,3405 \mathrm{c}$ & $0,1610 \mathrm{c}$ & $0,0130 \mathrm{c}$ & $2,4636 a$ & $0,6220 b$ & $0,1399 \mathrm{c}$ & $0,0822 \mathrm{c}$ & $0,0229 \mathrm{c}$ \\
\hline Diâmetro do fruto & $2,4636 a$ & $0,6220 \mathrm{~b}$ & $0,1399 \mathrm{c}$ & $0,0822 \mathrm{c}$ & $0,0229 \mathrm{c}$ & $2,4636 a$ & $0,6220 b$ & $0,1399 \mathrm{c}$ & $0,0822 \mathrm{c}$ & $0,0229 \mathrm{c}$ \\
\hline
\end{tabular}

\footnotetext{
${ }^{(1)}$ Valores seguidos de letras iguais, na linha, em cada ciclo, não diferem entre si pelo teste de Bartlett, a $5 \%$ de probabilidade.
} 
do tamanho de parcela considerado prático e válido em termos de área, recursos disponíveis e quantidade de unidades experimentais que atendam às exigências de número de graus de liberdade, com mínimo de 10 para o resíduo (Pimentel-Gomes, 2000).
As estimativas de tamanho de parcela variaram com as características avaliadas, método empregado e ciclo de produção, e corroboraram os estudos realizados por Genizi et al. (1980), Ortiz (1995) e Nokoe \& Ortiz (1998).

Tabela 3. Estimativas da diferença d, detectável (\% da média) entre dois tratamentos, das características fenotípicas avaliadas em dois ciclos de produção em bananeira 'Tropical', em diferentes tamanhos de parcela, com dois números de repetições (r) e com seis tratamentos, em Guanambi, BA, em 2005 e 2006.

\begin{tabular}{|c|c|c|c|c|c|c|c|c|c|c|c|c|c|c|c|}
\hline \multirow{2}{*}{$\begin{array}{l}\text { Caractisticas } \\
\text { fenotípicas }\end{array}$} & \multirow[t]{2}{*}{ Repetições } & \multicolumn{14}{|c|}{ Tamanho de parcela (UB) } \\
\hline & & 1 & 2 & 3 & 4 & 5 & 6 & 8 & 9 & 10 & 12 & 15 & 18 & 20 & 24 \\
\hline \multirow{3}{*}{ Altura da planta } & \multicolumn{15}{|c|}{$1^{\circ}$ ciclo } \\
\hline & 3 & 12,5 & 8,6 & 6,0 & 6,2 & 5,7 & 4,1 & 4,5 & 3,6 & 4,3 & 3,1 & 2,9 & 2,6 & 3,2 & 2,3 \\
\hline & 6 & 8,3 & 5,7 & 4,0 & 4,1 & 3,8 & 2,8 & 3,0 & 2,4 & 2,9 & 2,1 & 2,1 & 1,9 & 1,7 & 2,1 \\
\hline \multirow[t]{2}{*}{ Perímetro do pseudocaule } & 3 & 13,1 & 8,0 & 6,3 & 5,3 & 4,8 & 4,0 & 3,3 & 3,6 & 3,2 & 2,8 & 2,6 & 2,5 & 2,2 & 1,8 \\
\hline & 6 & 8,7 & 5,3 & 4,2 & 3,5 & 3,2 & 2,7 & 2,2 & 2,4 & 2,1 & 1,8 & 1,7 & 1,6 & 1,5 & 1,2 \\
\hline \multirow{2}{*}{ Folhas vivas no florescimento } & 3 & 30,2 & 18,8 & 13,5 & 11,4 & 10,1 & 8,9 & 7,2 & 5,8 & 6,6 & 5,4 & 5,1 & 4,0 & 4,9 & 3,8 \\
\hline & 6 & 20,1 & 12,5 & 9,0 & 7,5 & 6,7 & 5,9 & 4,8 & 3,9 & 4,4 & 3,6 & 3,6 & 3,4 & 2,7 & 3,2 \\
\hline \multirow[t]{2}{*}{ Filhos emitidos } & 3 & 60,0 & 33,3 & 22,6 & 18,1 & 16,2 & 13,2 & 10,0 & 9,6 & 9,7 & 7,3 & 6,7 & 5,2 & 5,8 & 4,1 \\
\hline & 6 & 39,8 & 22,1 & 15,0 & 12,0 & 10,7 & 8,8 & 6,7 & 6,4 & 6,5 & 4,8 & 4,5 & 3,5 & 3,8 & 2,7 \\
\hline \multirow[t]{2}{*}{ Folhas vivas na colheita } & 3 & 34,5 & 20,3 & 13,8 & 11,5 & 10,0 & 7,8 & 7,4 & 6,1 & 6,3 & 4,4 & 4,3 & 3,5 & 3,8 & 2,9 \\
\hline & 6 & 22,9 & 13,5 & 9,1 & 7,7 & 6,6 & 5,2 & 4,9 & 4,1 & 4,2 & 2,9 & 2,8 & 2,3 & 2,6 & 1,9 \\
\hline \multirow[t]{2}{*}{ Peso do cacho } & 3 & 39,6 & 23,3 & 16,8 & 13,4 & 11,4 & 10,5 & 7,9 & 7,4 & 7,1 & 6,2 & 5,3 & 5,0 & 4,0 & 3,6 \\
\hline & 6 & 26,3 & 15,5 & 11,2 & 8,9 & 7,6 & 7,0 & 5,3 & 4,9 & 4,7 & 4,1 & 3,5 & 3,3 & 2,6 & 2,4 \\
\hline \multirow{2}{*}{ Peso das pencas } & 3 & 41,6 & 24,2 & 17,3 & 13,9 & 11,8 & 10,6 & 8,2 & 7,2 & 7,3 & 6,1 & 5,2 & 4,8 & 4,1 & 3,5 \\
\hline & 6 & 27,6 & 16,1 & 11,5 & 9,2 & 7,8 & 7,1 & 5,4 & 4,8 & 4,9 & 4,1 & 3,4 & 3,2 & 2,7 & 2,3 \\
\hline \multirow[t]{2}{*}{ Número de pencas } & 3 & 25,5 & 13,5 & 10,3 & 7,3 & 5,6 & 5,5 & 4,4 & 4,4 & 3,1 & 3,0 & 2,3 & 2,5 & 1,9 & 1,9 \\
\hline & 6 & 16,9 & 8,9 & 6,8 & 4,8 & 3,7 & 3,6 & 2,9 & 2,9 & 2,1 & 2,0 & 1,6 & 1,7 & 1,3 & 1,3 \\
\hline \multirow{2}{*}{ Número de frutos } & 3 & 34,3 & 20,0 & 14,0 & 12,2 & 9,8 & 8,3 & 7,4 & 6,0 & 6,6 & 5,0 & 4,2 & 3,5 & 4,7 & 3,4 \\
\hline & 6 & 22,8 & 13,3 & 9,3 & 8,1 & 6,5 & 5,5 & 4,9 & 4,0 & 4,4 & 3,3 & 2,8 & 2,3 & 3,1 & 2,3 \\
\hline Peso da segunda penca & 3 & 40,4 & 22,8 & 15,5 & 11,7 & 10,7 & 8,8 & 6,2 & 6,3 & 5,8 & 4,9 & 4,7 & 3,7 & 2,8 & 2,8 \\
\hline & 6 & 26,8 & 15,1 & 10,3 & 7,7 & 7,1 & 5,9 & 4,1 & 4,2 & 3,8 & 3,3 & 3,1 & 2,4 & 1,9 & 1,9 \\
\hline Peso do fruto & 3 & 36,6 & 20,2 & 14,2 & 10,6 & 9,3 & 8,4 & 5,8 & 5,5 & 5,5 & 4,2 & 4,1 & 3,1 & 3,3 & 2,6 \\
\hline & 6 & 24,3 & 13,4 & 9,4 & 7,0 & 6,2 & 5,6 & 3,8 & 3,6 & 3,7 & 2,8 & 2,7 & 2,0 & 2,2 & 1,7 \\
\hline Comprimento do fruto & 3 & 25,9 & 14,8 & 9,4 & 7,6 & 6,7 & 5,4 & 3,9 & 3,6 & 3,6 & 2,7 & 2,5 & 2,2 & 1,7 & 1,2 \\
\hline & 6 & 17,2 & 9,8 & 6,3 & 5,0 & 4,4 & 3,6 & 2,6 & 2,4 & 2,4 & 1,8 & 1,7 & 1,5 & 1,1 & 0,8 \\
\hline Diâmetro do fruto & 3 & 15,2 & 8,8 & 6,0 & 4,6 & 4,2 & 3,4 & 2,7 & 2,3 & 2,5 & 1,8 & 1,8 & 1,4 & 1,4 & 1,2 \\
\hline & 6 & 10,1 & 5,8 & 4,0 & 3,1 & 2,8 & 2,3 & 1,8 & 1,6 & 1,7 & 1,2 & 1,2 & 0,9 & 1,0 & 0,8 \\
\hline & & & & & & & & $2^{-}$cicl & & & & & & & \\
\hline Altura da planta & 3 & 16,0 & 11,9 & 10,1 & 9,1 & 8,8 & 8,1 & 7,3 & 6,3 & 7,0 & 6,6 & 6,5 & 5,5 & 5,3 & 5,4 \\
\hline & 6 & 10,6 & 7,9 & 6,7 & 6,0 & 5,8 & 5,4 & 4,8 & 4,2 & 4,6 & 4,4 & 4,3 & 3,6 & 3,5 & 3,6 \\
\hline Perímetro do pseudocaule & 3 & 19,3 & 14,1 & 11,7 & 10,5 & 10,0 & 9,2 & 8,3 & 7,5 & 7,9 & 7,6 & 7,3 & 6,1 & 6,2 & 6,2 \\
\hline & 6 & 12,8 & 9,3 & 7,8 & 7,0 & 6,6 & 6,1 & 5,5 & 5,0 & 5,3 & 5,0 & 4,8 & 4,1 & 4,1 & 4,1 \\
\hline Folhas vivas no florescimento & 3 & 29,1 & 17,2 & 11,5 & 9,3 & 8,5 & 7,5 & 5,8 & 4,7 & 4,3 & 4,3 & 3,8 & 3,0 & 2,7 & 2,8 \\
\hline & 6 & 19,3 & 11,4 & 7,6 & 6,2 & 5,7 & 5,0 & 3,9 & 3,1 & 2,9 & 2,8 & 2,5 & 2,0 & 1,8 & 1,8 \\
\hline Filhos emitidos & 3 & 79,8 & 41,0 & 25,1 & 20,2 & 16,7 & 12,6 & 10,4 & 7,9 & 8,9 & 7,4 & 6,1 & 2,6 & 5,1 & 4,0 \\
\hline & 6 & 53,0 & 27,2 & 16,6 & 13,4 & 11,1 & 8,3 & 6,9 & 5,3 & 5,9 & 4,9 & 4,1 & 1,7 & 3,4 & 2,6 \\
\hline Folhas vivas na colheita & 3 & 42,1 & 24,7 & 18,5 & 16,2 & 14,0 & 11,0 & 10,6 & 8,5 & 8,1 & 7,9 & 6,7 & 5,9 & 5,1 & 5,5 \\
\hline & 6 & 27,9 & 16,4 & 12,3 & 10,8 & 9,3 & 7,3 & 7,0 & 5,6 & 5,4 & 5,2 & 4,5 & 3,9 & 3,4 & 3,6 \\
\hline Peso do cacho & 3 & 47,3 & 29,2 & 21,8 & 19,5 & 16,3 & 13,4 & 13,1 & 10,4 & 10,4 & 9,3 & 8,6 & 6,8 & 7,5 & 6,7 \\
\hline & 6 & 31,4 & 19,4 & 14,5 & 13,0 & 10,8 & 8,9 & 8,8 & 9,0 & 7,2 & 6,6 & 5,7 & 4,5 & 5,0 & 4,5 \\
\hline Peso das pencas & 3 & 50,5 & 31,3 & 23,2 & 21,0 & 17,4 & 14,1 & 14,0 & 11,0 & 11,0 & 9,9 & 9,1 & 7,1 & 8,0 & 7,1 \\
\hline & 6 & 33,5 & 20,7 & 15,4 & 13,9 & 11,6 & 9,4 & 9,3 & 7,3 & 7,3 & 6,5 & 6,0 & 4,7 & 5,3 & 4,7 \\
\hline Número de pencas & 3 & 27,2 & 14,5 & 9,6 & 7,9 & 6,5 & 5,2 & 4,8 & 3,2 & 3,4 & 2,8 & 2,5 & 1,9 & 1,8 & 1,7 \\
\hline & 6 & 18,1 & 9,6 & 6,4 & 5,3 & 4,3 & 3,4 & 3,2 & 2,1 & 2,2 & 1,9 & 1,6 & 1,3 & 1,2 & 1,2 \\
\hline Número de frutos & 3 & 41,7 & 23,0 & 15,3 & 12,9 & 10,2 & 8,4 & 7,6 & 5,7 & 5,9 & 4,8 & 4,3 & 3,4 & 3,4 & 3,2 \\
\hline & 6 & 27,7 & 15,3 & 10,2 & 8,5 & 6,7 & 5,6 & 5,1 & 3,8 & 3,9 & 3,2 & 2,9 & 2,3 & 2,2 & 2,1 \\
\hline Peso da segunda penca & 3 & 49,8 & 30,5 & 20,2 & 19,4 & 16,2 & 12,8 & 11,9 & 8,5 & 10,3 & 8,3 & 6,8 & 5,9 & 6,2 & 5,2 \\
\hline & 6 & 33,1 & 20,2 & 13,4 & 12,9 & 10,7 & 8,5 & 7,9 & 5,7 & 6,8 & 5,5 & 4,5 & 3,9 & 4,1 & 3,4 \\
\hline Peso do fruto & 3 & 50,0 & 30,4 & 21,3 & 20,5 & 16,2 & 13,6 & 12,3 & 8,7 & 10,8 & 9,1 & 6,5 & 6,1 & 7,1 & 5,2 \\
\hline & 6 & 33,2 & 20,2 & 14,1 & 13,6 & 10,7 & 9,0 & 8,1 & 5,8 & 7,2 & 6,0 & 4,3 & 4,0 & 4,7 & 3,5 \\
\hline Comprimento do fruto & 3 & 27,7 & 14,9 & 9,7 & 8,6 & 6,5 & 5,0 & 4,5 & 3,2 & 3,7 & 2,6 & 1,8 & 1,8 & 2,2 & 1,3 \\
\hline & 6 & 18,4 & 9,9 & 6,5 & 5,7 & 4,3 & 3,3 & 3,0 & 2,1 & 2,5 & 1,7 & 1,2 & 1,2 & 1,4 & 0,8 \\
\hline Diâmetro do fruto & 3 & 17,9 & 11,6 & 7,4 & 7,7 & 6,4 & 5,1 & 4,7 & 3,4 & 4,4 & 3,4 & 2,7 & 2,6 & 2,7 & 2,2 \\
\hline & 6 & 11,9 & 7,7 & 4,9 & 5,1 & 4,2 & 3,4 & 3,1 & 2,3 & 2,9 & 2,3 & 1,8 & 1,7 & 1,8 & 1,4 \\
\hline
\end{tabular}


O método da máxima curvatura mostrou maior convergência dos valores estimados. Pelo método da máxima curvatura modificado estimaram-se tamanhos de parcela menores relativamente aos demais, comportamento também observado por outros autores (Viana et al., 2002; Henriques Neto et al., 2004). Os tamanhos de parcela estimados pelo método da comparação de variâncias mostraram maior variação entre os valores (Tabela 2).

Quanto à seleção do melhor método para estimativa do tamanho adequado de parcela, há muita divergência na literatura. Ortiz (1995) trabalhou com bananeira e considerou como mais adequado o método da comparação de variâncias, em relação ao método da máxima curvatura. Entretanto, Zanon \& Storck (2000), em estudos com eucalipto, e Lopes et al. (2005), com sorgo, consideraram o método da máxima curvatura modificado o mais adequado, opinião também compartilhada por Viana et al. (2002) em trabalho com mandioca, que argumentam como vantagens desse método: o estabelecimento de uma equação de regressão, que normalmente apresenta altos valores de coeficiente de determinação; o aumento da confiabilidade das estimativas; e a possibilidade de associação com a diferença entre médias a ser detectada como informação adicional importante em planejamento experimental. Aliados a esses argumentos, vale ressaltar outros inconvenientes concernentes aos demais métodos, discutidos anteriormente.

Em experimentos de avaliação de genótipos de bananeira, as características aqui estudadas são as normalmente mensuradas, o que demanda selecionar um tamanho de parcela que assegure a análise ajustada de todas elas. Conseqüentemente, respaldado nas estimativas de tamanho de parcela, pelo método da máxima curvatura modificado, e na diferença detectável entre médias de tratamentos para a característica mais crítica (maior variabilidade), parcelas com no máximo 6 UBs $\left(36 \mathrm{~m}^{2}\right)$ permitem avaliação com precisão.

\section{Conclusões}

1. A variabilidade aumenta entre os ciclos da planta-mãe e do filho, com reflexos nas estimativas de tamanho de parcela.

2. As estimativas de tamanho de parcela variam com o método utilizado, a característica avaliada e o ciclo de produção.
3. As características de rendimento exibem valores mais concordantes e menor oscilação nas estimativas do tamanho adequado de parcela, comparativamente às características vegetativas, para os ciclos e métodos testados.

4. O método da máxima curvatura modificado apresenta estimativas mais ajustadas.

5. Parcelas com seis unidades básicas são apropriadas para avaliar com precisão os descritores fenotípicos considerados em bananeira.

\section{Referências}

DANIELS, J. Que variedad de banano debo cultivar? Infomusa, v.9, p.31-33, 2000.

DONATO, S.L.R.; SILVA, S. de O. e; LUCCA FILHO, O.A.; LIMA, M.B.; DOMINGUES, H.; ALVES, J. da S. Comportamento de variedades e híbridos de bananeira (Musa spp.), em dois ciclos de produção no Sudoeste da Bahia. Revista Brasileira de Fruticultura, v.28, p.139-144, 2006.

FAO. Food and Agricultural Organization. FaoStat. Disponível em: $<$ http://faostat.fao.org/site/601/default.aspx>. Acesso em: 19 abr. 2008.

FEDERER, W.T. Experimental design: theory and application. $2^{\text {nd }}$ ed. New York: Macmillan Company, 1963. 544p.

GENIZI, A.; LAHAV, E.; PUTTER, J. Determination of optimal plot size in banana experiments. Fruits, v.35, p.25-28, 1980.

GOMEZ, K.A.; GOMEZ, A.A. Statistical procedures for agricultural research. $2^{\text {nd }}$ ed. New York: John Wiley, 1984. 680p.

HATHEWAY, W.H. Convenient plot size. Agronomy Journal, v.53, p.279-280, 1961.

HENRIQUES NETO, D.; SEDIYAMA, T.; SOUZA, M.A. de; CECON, P.R.; YAMANAKA, C.H.; SEDIYAMA, M.A.N.; VIANA, A.E. Tamanho de parcelas em experimentos com trigo irrigado sob plantio direto e convencional. Pesquisa Agropecuária Brasileira, v.39, p.517-524, 2004.

LE CLERG, E.L. Significance of experimental design in plant breeding. In: FREY, K.J. (Ed.). Plant breeding symposium. Ames: Iowa State University, 1967. p.243-313.

LEITE, J.B.V.; SILVA, S. de O. e; ALVES, E.; LINS, R.D.; JESUS, O.N. de. Caracteres da planta e do cacho de genótipos de bananeira, em quatro ciclos de produção em Belmonte, Bahia. Revista Brasileira de Fruticultura, v.25, p.443-447, 2003.

LIMA, M.B.; SILVA, S. de O. e; JESUS, O.N. de; OLIVEIRA, W.S.J. de; GARRIDO, M.S.; AZEVEDO, R.L. de. Avaliação de cultivares e híbridos de bananeira no Recôncavo Baiano. Ciência e Agrotecnologia, v.29, p.515-520, 2005.

LIMA NETO, F.P.; SILVA, S. de O. e; FLORES, J.C. de O.; JESUS, O.N. de; PAIVA, L.E. Relações entre caracteres de rendimento e de desenvolvimento em genótipos de bananeira. Magistra, v.15, p.275-281, 2003. 
LOPES, S.J.; STORCK, L.; LÚCIO, A.D.C.; LORENTZ, L.H.; LOVATO, C.; DIAS, V. de O. Tamanho de parcela para produtividade de grãos de sorgo granífero em diferentes densidades de plantio. Pesquisa Agropecuária Brasileira, v.40, p.525-530, 2005.

MEIER, V.D.; LESSMAN, K.J. Estimation of optimum field plot shape and size for testing yield in Crambe abyssinica Hochst. Crop Science, v.11, p.648-650, 1971.

NOKOE, S.; ORTIZ, R. Optimum plot size for banana trials. Hortscience, v.33, p.130-132, 1998.

OLIVEIRA, C.A.P. de; PEIXOTO, C.P.; SILVA, S. de O. e; LEDO, C.A. da S.; SALOMÃO, L.C.C. Genótipos de bananeira em três ciclos de produção na Zona da Mata mineira. Pesquisa Agropecuária Brasileira, v.42, p.173-181, 2007.

ORTIZ, R. Morphological variation in Musa germplasm. Genetic Resources and Crop Evolution, v.44, p.393-404, 1997.

ORTIZ, R. Plot techniques for assessment of bunch weight in banana trials under two systems of crop management. Agronomy Journal, v.87, p.63-69, 1995.

PEREIRA, L.V.; ALVARENGA, A.A.; MATOS, L.E.S.; SILVA, C.R.R. e. Avaliação de cultivares de bananeira (Musa spp.,AAB) em três locais do Estado de Minas Gerais. Ciência e Agrotecnologia, v.26, p.1373-1382, 2002. (Edição Especial).

PIMENTEL-GOMES, F. Curso de estatística experimental. 14.ed. Piracicaba: Nobel, 2000. 477p.

SILVA, S. de O. e; ALVES, E.J.; LIMA, M.B.; SILVEIRA, J.R.S. Bananeira. In: BRUCKNER, C.H. (Ed.). Melhoramento de fruteiras tropicais. Viçosa: UFV, 2002. p.101-157.

SILVA, S. de O. e; CARVALHO, P.C.L. de; SHERPHERD, K.; ALVES, E.J.; OLIVEIRA, C.A.P. de; CARVALHO, J.A.B.S.
Catálogo de germoplasma de bananeira (Musa spp.). Cruz das Almas: Embrapa-CNPMF, 1999. 100p. (Embrapa-CNPMF. Documentos, 90).

SILVA, S. de O. e; ROCHA, S.A.; ALVES, E.J.; CREDICO, M. di; PASSOS, A.R. Caracterização morfológica e avaliação de cultivares e híbridos de bananeira. Revista Brasileira de Fruticultura, v.22, p.161-169, 2000.

SIRISENA, J.A.; SENANAYAKE, S.G.N. Estimation of variability parameters within 'Mysore' banana clones and their implication for crop improvement. Scientia Horticulturae, v.84, p.49-66, 2000.

SMITH, H.F. An empirical law describing heterogeneity in the yields of agricultural crops. Journal of Agricultural Science, v.28, p.1-23, 1938.

SPEIJER, P.R.; SSANGO, F.; KAJUMBRA, C.; GOLD, C.S. Optimum sample size for Pratylenchus goodeyi (Cobb) Sher and Allen density and damage assessment in highland banana (Musa AAA) in Uganda. African Crop Science Journal, v.6, p.283-291, 1998.

TENKOUANO, R.; ORTIZ, R.; BAIYERI, K.P. Phenotypic and genetic correlations in Musa populations in Nigeria. African Crop Science Journal, v.10, p.121-132, 2002.

VALLEJO, R.L.; MENDOZA, H.A. Plot technique studies on sweetpotato yield trials. Journal of the American Society for Horticultural Science, v.117, p.508-511, 1992.

VIANA, A.E.S.; SEDIYAMA, T.; CECON, P.R.; LOPES, S.C.; SEDIYAMA, M.A.N. Estimativas de tamanho de parcela em experimentos com mandioca. Horticultura Brasileira, v.20, p.58-63, 2002.

ZANON, M.L.B.; STORCK, L. Tamanho ótimo de parcelas experimentais para Eucalyptus saligna Smith em dois estádios de desenvolvimento. Cerne, v.6, p.104-111, 2000.

Recebido em 21 de abril de 2008 e aprovado em 29 de julho de 2008 